\title{
Вплив використання спеціальних вправ на психофізіологічні показники юних боксерів 15-16 років
}

\author{
Юрій Шестак \\ Вячеслав Мулик \\ Дар'я Окунь
}

Харківська державна академія фізичної культури, Харків, Україна

\begin{abstract}
Мета: визначити ефективність застосування спеціальних вправ з використанням боксерських споряджень протягом річного макроциклу у юних боксерів 15-16 років.

Матеріал і методи: дослідження проводилися із залученням юних боксерів 15-16 років, що склали контрольну (12 спортсменів) і експериментальну (12 спортсменів) групи, які здійснювали річний тренувальний процес за програмою ДЮСШ, але в експериментальній групі в кінці кожного тренування використовувалися вправи із застосуванням боксерських споряджень (вправи з мішком і грушею; з настінною подушкою; пневматичною грушею; вправи з м'ячем на гумках; вправи з малим підвісним м'ячем). Початкове і прикінцеве вимірювання психофізіологічних показників здійснювалося після тренування з великим навантаженням, яке використовувалося у боксерів обох груп.

Результати: отримані результати дозволяють розширити методику використання спеціальних вправ для розвитку швидкісно-силових якостей відповідно до специфіки виду спорту. Визначено доцільність використання вправ спеціальної швидкісно-силової спрямованості у юних боксерів 15-16 років наприкінці тренувального заняття на фоні втоми.

Висновки: підтверджено покращення результатів психофізіологічних показників, які є складовими рухової діяльності боксерів (часу простої реакції на звук і світло; проби Ромберга, показників тесту Шульте, концентрації та переключення уваги за тестом Бурдона).
\end{abstract}

Ключові слова: юні боксери, психофізіологічні показники, спеціальні боксерські спорядження, швидкісно-силові якості.

\section{Вступ}

Фізична підготовка боксера $є$ основним чинником, що забезпечує якість технічної, тактичної та психологічної підготовленості, рівень розвитку всіх інших компонентів майстерності $[1 ; 4 ; 15]$.

Методика розвитку швидкісно-силових якостей пов'язується із забезпеченням необхідної функціональної підготовки організму для вдосконалення техніко-тактичної майстерності і планомірного підвищення швидкості виконання змагальної вправи. Спеціальні дослідження $[2 ; 10 ; 14]$ свідчать про неузгодженість думок тренерів у різних видах спорту щодо тренувального впливу найбільш популярних засобів спеціальної фізичної підготовки (СФП). Очевидно, причина такого становища криється в нестачі знань про фізіологічні механізми, що лежать в основі спеціальної працездатності спортсмена і засобів, що визначають тренувальний ефект [3; 6; 7].

Сьогодні спортсмени широко використовують у тренуванні змагальні вправи з високою інтенсивністю зусиль [8]. Поряд з іншими і не менш важливими перевагами такий прийом виступає як вельми ефективний засіб СФП, бо важко придумати що-небудь більш спеціальне у цьому відношенні. Тому виконання змагальної вправи у тренуванні з максимальною інтенсивністю зусиль і високою швидкістю є важливим засобом системи СФП, але вимагає наукового і методичного обґрунтування [13].

За ступенем відповідності режиму роботи організму при виконанні змагальної вправи має сенс виділити три групи засобів СФП [12; 18]: специфічні - різні форми (варіанти) виконання основної спортивної вправи із завданням пристосування організму до режиму його роботи в умовах змагань; спеціалізовані - адекватні до змагальних умов за найбільш істотними руховими і функціональними параметрами режиму роботи організму; неспецифічні - формально не відповідають змагальній вправі за руховою організацією, але які сприятимуть розвитку функціональних можливостей організму в потрібному напрямку; їх завдання полягає в посиленні тренувального ефекту спеціалізованих засобів за рахунок додаткового вибіркового впливу на ті чи інші фізіологічні системи і функції організму.

Практично при підборі засобів СФП слід керуватися принципом динамічної відповідності [5; 9; 17], згідно з яким вони повинні бути адекватні змагальній вправі за наступними критеріями: групам м'язів, що залучаються до роботи, амплітуда і напрям руху; акцентована ділян- 
ка амплітуди руху; величина зусилля і час його розвитку; швидкість руху, режим роботи м'язів. Виходячи з цих критеріїв, визначається вихідне положення, кінематична схема рухів, величина зовнішнього опору, характер прояву зусиль і, нарешті, метод вправи [12; 16].

У свою чергу П. Анохін визначає, що найбільш ефективним $€$ використання спеціально-підготовчих вправ, які за структурою рухів відповідають змагальній вправі.

Мета дослідження - визначити ефективність застосування спеціальних вправ з використанням боксерських споряджень протягом річного макроциклу у юних боксерів 15-16 років.

\section{Матеріал і методи дослідження}

У проведених дослідженнях нами доповнено ще двома положеннями про доцільність використання спеціальних вправ, які також відтворюють не тільки структуру рухів, але і структуру зусиль, а також впливу спеціальних вправ на формування функціональної системи (серцевосудинної, дихальної, нервово-м'язової), що забезпечує змагальну діяльність в обраному виді спорту. Саме підбір швидкісно-силових вправ боксерів з вирішення зазначених питань $€$ актуальним у спортивному тренуванні.

У зв'язку з цим використання швидкісно-силових вправ із застосуванням спеціальних пристроїв будуть сприяти покращенню психофізіологічних показників та сприятимуть формуванню спеціальної підготовленості.

\section{Результати дослідження}

Основною особливістю експериментальної методики було застосування спеціальних вправ, які формують рухові дії боксерів наприкінці тренувального заняття. Зазначене зумовлено тим, що у боксерів дуже важливо у кінці поєдинку проявляти швидкісно-силові якості, які впливають на визначення переможця. Тому саме використання спеціальних вправ у кінці тренування на фоні втоми формують прояв спеціальних швидкісно-силових якостей, що за структурою рухів, структурою зусиль та формуванням функціональної системи, специфічної для боксу, є ефективним науковим дослідженням. Представлені раніше [11] наукові дослідження дозволили визначити вплив зазначених спеціальних боксерських споряджень на показники загальної фізичної підготовки, під час яких визначався їх вплив на психофізіологічні показники.

Проведене тестування психофізіологічних показників по початку річного макроциклу у контрольній і експериментальній групах не виявило достовірної $(p>0,05)$ різниці між досліджуваними групами. Проведений річний тренувальний процес юних боксерів 15-16 років контрольної групи за програмою дЮСШ позитивно вплинув на формування психологічних показників, але достовірні зрушення отримано в показниках проби Ромберга $(t=2,26 ; p<0,05)$ та переключення уваги за тестом Бурдона (t=2,19; $p<0,05)$.

Натомість використання у кінці кожного заняття спеціальних вправ швидкісно-силової спрямованості дозволило на кінець дослідження у юних боксерів 1516 років експериментальної групи у показниках: проба Ромберга на 2,4 c (t=4,29; $p<0,01)$, час простої реакції на звук на $0,11 \mathrm{c}(\mathrm{t}=2,44 ; \mathrm{p}<0,05)$, час реакції вибору на 0,27 $\mathrm{c}(\mathrm{t}=2,70 ; \mathrm{p}<0,05) ;$ час простої реакції на світло на 0,08 c $(\mathrm{t}=2,22 ; \mathrm{p}<0,05)$; ефективність роботи за тестом Шульте на 7,4 ум.од. ( $t=4,09 ; \mathrm{p}<0,01)$; ступінь впрацьованості за тестом Шульте на 0,25 ум.од. ( $t=3,47 ; p<0,01)$; пси-

Таблиця 1

Психофізіологічні показники контрольної групи на початку і на кінець річного макроциклу $(\mathrm{n} 1=\mathrm{n} 2=12) \overline{\mathrm{x}} \pm \mathrm{m}$

\begin{tabular}{|l|l|l|l|l|l|}
\hline$№$ & Показники & На початок & На кінець & \multicolumn{2}{|l|}{ Оцінка достовірності } \\
\hline $3 / \mathrm{p}$ & & & & $\mathrm{t}$ & $\mathrm{p}$ \\
\hline 1 & Індекс Руф'є, ум.од. & $7,92 \pm 0,26$ & $7,01 \pm 0,24$ & 1,17 & $>0,05$ \\
\hline 2 & Проба Ромберга, с & $13,6 \pm 0,32$ & $14,8 \pm 0,43$ & 2,26 & $<0,05$ \\
\hline 3 & Час простої реакції на звук, с & $0,35 \pm 0,03$ & $0,31 \pm 0,03$ & 1,00 & $>0,05$ \\
\hline 4 & Час реакції вибору,с & $1,25 \pm 0,10$ & $1,21 \pm 0,07$ & 0,37 & $>0,05$ \\
\hline 5 & $\begin{array}{l}\text { Час простої реакції на світло, } \\
\text { с }\end{array}$ & $0,37 \pm 0,04$ & $0,35 \pm 0,03$ & 0,40 & $>0,05$ \\
\hline 6 & $\begin{array}{l}\text { Ефективність роботи за } \\
\text { тестом Шульте, ум.од. }\end{array}$ & $7,04 \pm 1,46$ & $67,5 \pm 1,32$ & 1,48 & $>0,05$ \\
\hline 7 & $\begin{array}{l}\text { Ступінь впрацьованості за } \\
\text { тестом Шульте, ум.од. }\end{array}$ & $1,01 \pm 0,6$ & $0,92 \pm 0,05$ & 1,15 & $>0,05$ \\
\hline 8 & $\begin{array}{l}\text { Психічна стійкість за тестом } \\
\text { Шульте, ум.од. }\end{array}$ & $0,92 \pm 0,05$ & $0,88 \pm 0,05$ & 0,57 & $>0,05$ \\
\hline 9 & $\begin{array}{l}\text { Концентрація уваги за } \\
\text { тестом Бурдона, ум.од. }\end{array}$ & $236,6 \pm 5,10$ & $252,6 \pm 5,46$ & 2,07 & $>0,05$ \\
\hline 10 & $\begin{array}{l}\text { Переключення уваги за } \\
\text { тестом Бурдона, ум.од. }\end{array}$ & $35,4 \pm 1,12$ & $32,5 \pm 1,08$ & 2,19 & $<0,05$ \\
\hline 11 & $\begin{array}{l}\text { Теппінг-тест, частота рухів, } \\
\text { (кількість разів) }\end{array}$ & $4,62 \pm 0,15$ & $4,78 \pm 0,16$ & 0,79 & $<0,05$ \\
\hline
\end{tabular}


Таблиця 2

Психофізіологічні показники юних боксерів 15-16 років експериментальної групи на початок і на кінець річного макроциклу $(n 1=n 2=12) \bar{x} \pm m$

\begin{tabular}{|l|l|l|l|l|l|}
\hline \multirow{2}{*}{$\begin{array}{l}\text { № } \\
3 / \mathrm{p}\end{array}$} & Показники & На початок & На кінець & \multicolumn{2}{|l|}{$\begin{array}{l}\text { Оцінка } \\
\text { достовірності }\end{array}$} \\
\cline { 5 - 6 } & & & & $\mathrm{t}$ & $\mathrm{p}$ \\
\hline 1 & Індекс Руф'є, ум.од. & $7,44 \pm 0,25$ & $6,94 \pm 0,23$ & 1,17 & $>0,05$ \\
\hline 2 & Проба Ромберга, с & $13,1 \pm 0,33$ & $15,5 \pm 0,45$ & 4,29 & $<0,01$ \\
\hline 3 & Час простої реакції на звук, с & $0,34 \pm 0,04$ & $0,23 \pm 0,02$ & 2,44 & $<0,05$ \\
\hline 4 & Час реакції вибору,с & $1,27 \pm 0,08$ & $1,00 \pm 0,06$ & 2,70 & $<0,05$ \\
\hline 5 & Час простої реакції на світло, с & $0,35 \pm 0,03$ & $0,27 \pm 0,02$ & 2,22 & $<0,05$ \\
\hline 6 & $\begin{array}{l}\text { Ефективність роботи за тестом } \\
\text { Шульте, ум. од. }\end{array}$ & $69,5 \pm 1,35$ & $62,1 \pm 1,21$ & 4,09 & $<0,01$ \\
\hline 7 & $\begin{array}{l}\text { Ступінь впрацьованості за } \\
\text { тестом Шульте, ум.од. }\end{array}$ & $1,03 \pm 0,06$ & $0,78 \pm 0,04$ & 3,47 & $<0,01$ \\
\hline 8 & $\begin{array}{l}\text { Психічна стійкість за тестом } \\
\text { Шульте, ум.од. }\end{array}$ & $0,94 \pm 0,05$ & $0,74 \pm 0,04$ & 3,13 & $<0,01$ \\
\hline 9 & $\begin{array}{l}\text { Концентрація уваги за тестом } \\
\text { Бурдона, ум.од. }\end{array}$ & $238,8 \pm 5,04$ & $271,6 \pm 5,01$ & 4,62 & $<0,001$ \\
\hline 10 & $\begin{array}{l}\text { Переключення уваги за тестом } \\
\text { Бурдона, ум.од. }\end{array}$ & $34,8 \pm 1,12$ & $28,7 \pm 1,02$ & 4,04 & $<0,01$ \\
\hline 11 & $\begin{array}{l}\text { Теппінг-тест, частота рухів, } \\
\text { (кількість разів) }\end{array}$ & $4,60 \pm 0,15$ & $5,06 \pm 0,17$ & 2,00 & $>0,05$ \\
\hline
\end{tabular}

Таблиця 3

Психофізіологічні показники юних боксерів 15-16 років контрольної і експериментальної групи на кінець річного макроциклу $(\mathrm{n} 1=\mathrm{n} 2=12) \overline{\mathbf{x}} \pm \mathrm{m}$

\begin{tabular}{|l|l|l|l|l|l|}
\hline $\begin{array}{l}\text { № } \\
3 / \mathrm{p}\end{array}$ & Показники & Контр.гр. & Експер.група & \multicolumn{2}{|l|}{ Оцінка достовірності } \\
\hline 1 & & & $\mathrm{t}$ & $\mathrm{p}$ \\
\hline 2 & Пндекс Руф'є, ум.од. & $7,01 \pm 0,24$ & $6,94 \pm 0,23$ & 0,21 & $>0,05$ \\
\hline 3 & Проба Ромберга, с & $14,8 \pm 0,43$ & $15,5 \pm 0,45$ & 1,11 & $>0,05$ \\
\hline 4 & Час реакції вибору, с & $1,21 \pm 0,07$ & $1,00 \pm 0,06$ & 2,33 & $<0,05$ \\
\hline 5 & Час простої реакції на світло, с & $0,35 \pm 0,03$ & $0,27 \pm 0,02$ & 2,22 & $<0,05$ \\
\hline 6 & $\begin{array}{l}\text { Ефективність роботи за тестом } \\
\text { Шульте, ум. од. }\end{array}$ & $67,5 \pm 1,32$ & $62,1 \pm 1,21$ & 3,02 & $<0,05$ \\
\hline 7 & $\begin{array}{l}\text { Ступінь впрацьованості за } \\
\text { тестом Шульте, ум.од. }\end{array}$ & $0,92 \pm 0,06$ & $0,78 \pm 0,04$ & 2,19 & $<0,05$ \\
\hline 8 & $\begin{array}{l}\text { Психічна стійкість за тестом } \\
\text { Шульте, ум.од. }\end{array}$ & $0,88 \pm 0,05$ & $0,74 \pm 0,04$ & 2,19 & $<0,05$ \\
\hline 9 & $\begin{array}{l}\text { Концентрація уваги за тестом } \\
\text { Бурдона, ум.од. }\end{array}$ & $252,5 \pm 5,46$ & $271,6 \pm 5,01$ & 2,58 & $<0,05$ \\
\hline 10 & $\begin{array}{l}\text { Переключення уваги за тестом } \\
\text { Бурдона, ум.од. }\end{array}$ & $32,0 \pm 1,08$ & $28,7 \pm 1,02$ & 2,21 & $<0,05$ \\
\hline 11 & $\begin{array}{l}\text { Теппінг-тест, частота рухів, } \\
\text { (кількість разів) }\end{array}$ & $4,78 \pm 0,16$ & $5,06 \pm 0,17$ & 1,22 & $>0,05$ \\
\hline
\end{tabular}


хічна стійкість за тестом Шульте на 0,20 ум.од. ( $\mathrm{t}=3,13$; $\mathrm{p}<0,01)$; концентрація уваги за тестом Бурдона на 32,8 ум.од. ( $t=4,62 ; p<0,001)$; переключення уваги за тестом Бурдона на 3,4 ум.од. (t=2,19; $\mathrm{p}<0,05)$ (табл. 2).

Порівняння психофізіологічних показників юних боксерів 15-16 років досліджуваних груп на кінець річного макроциклу, що визначалися після однакового навантаження в групах, свідчить про ефективність використання в кінці тренування спеціальних вправ. Так, за більшістю показників кращі результати отримано в часі простої реакції на звук $(t=2,22 ; p<0,05)$, часі реакції вибору ( $t=2,33 ; p<0,05)$, часі простої реакції на світло $(t=2,22 ; p<0,05)$, ефективності роботи за тестом Шульте $(\mathrm{t}=3,02 ; \mathrm{p}<0,05)$, ступені впрацьваності за тестом Шульте $(\mathrm{t}=2,19 ; \mathrm{p}<0,05)$, психічної стікості за тестом Шульте $(t=2,14 ; p<0,05)$, концентрації уваги за тестом Бурдона $(t=2,58 ; p<0,05)$, переключення уваги за тестом Бурдона $(t=2,21 ; p<0,05)$.

Таким чином, після впровадження експериментальної методики за більшістю психофізіологічних показників кращі результати отримано у юних боксерів, що ви- користовували спеціальні засоби тренувань у кінці тренувань на фоні втоми.

\section{Висновки / Дискусія}

Отримані результати дозволяють розширити методику використання спеціальних вправ для розвитку швидкісно-силових якостей відповідно до специфіки виду спорту. Визначено доцільність використання вправ спеціальної швидкісно-силової спрямованості у юних боксерів 15-16 років наприкінці тренувального заняття на фоні втоми. Зазначене підтверджено результатами покращення психофізіологічних показників, які є складовими рухової діяльності боксерів (часу простої реакції на звук і світло; проби Ромберга, показників тесту Шульте, концентрації та переключення уваги за тестом Бурдона).

Перспективи подальших досліджень передбачають визначення впливу даної методики на результати тестування спеціальних рухових якостей та їх кореляційну залежність $з$ психофізиологічними якостями.

Конфлікт інтересів. Автори заявляють, що відсутній конфлікт інтересів, який може сприйматись таким, що може завдати шкоди неупередженості статті.

Джерела фінансування. Ця стаття не отримала фінансової підтримки від державної, громадської або комерційної організації.

\section{Список посилань}

1. Адашевский В. М., Ермаков С. С., Грицюк С. А. (2010), «Основные кинематические характеристики ударных действий в таэквондо", Физическое воспитание студентов, № 4, С. 3-5.

2. Аликин В. А., Корягина Ю. В. (2014), «Современные тенденции в медико-биологическом обеспечении высококвалифицированых спортсменов за рубежом", Весник спортивной науки, № 3, С. 50-55.

3. Анарбаев А. К. (2013), «Система подготовки борцов с учетом их квалификации и возраста», Успехи современного естествознания, №1, С 112-116.

4. Ашкинази С. М., Климов К. В. (2016), Технико-тактическая подготовка спортсменов в комплексних (смешанных) единоборствах: монография / Национальный государственный университет физической культуры, спорта и здоров'я им. П.Ф.Лесгафта, Санкт-Петербург; Военный институт физической культуры. Санкт-Петербург, (2-е издание, дополненное), 330 c.

5. Бакулев С. Е., Двейрина О. А., Афанасьева И. А., Чистяков В. А. (2013), «Прогнозирование успешности соревновательной деятельности боксеров на основе их «чувства времени»», Ученые записки университета им. П.Ф. Лесгафта, №9, С.23-27.

6. Бакулев С. Е., Таймазов В. А. (2006), «Генеалогические основы прогнозирования успешности соревновательной деятельности», Ученые записки университета им. П.Ф. Лесгафта, №19, С. 7-14.

7. Богатырев С. А. (2016), «Профессионально-прикладная физическая подготовка спортсменов, занимающихся спортивними видами единоборств", Педагогико-психологические и медико-биологические проблемы физической культуры и спорта, № 1 (38), С.8-17.

8. Гаськов А. В. (2004), Структура і зміст тренувально-змагальної діяльності в боксі: монографія / А.В. Гаськов, В.А. Кузьмін; Краснояр. держ. ун-т, Красноярськ, 112 с.

9. Киприч С. В., Беринчик Д. Ю. (2015), «Специфические характеристики функционального обеспечения специальной выносливости боксеров", Педагогика, психология и медико-биологические проблемы физического воспитания и спорта, № 3, C. $20-27$.

10. Лукьяненко В. П., Волков Р. А. (2013), «Биомеханические особенности ударних движений боксеров», Мир науки, культуры, образования, № 4 (41), С. 85-86.

11. Мулик В. В., Шестак Ю. С. Окунь Д. О.(2019), «Використання спеціальних боксерських споряджень у загальній фізичній підготовці юних боксерів 15-16 років», Науковий часопис НПУ імені М.П. Драгоманова, Випуск 11 (119), С.184-189.

12. Платонов В. Н. (2017), Двигательные качества и физическая подготовка спортсменов. Киев: Олимпийская литератуpa, $656 \mathrm{c}$.

13. Рябинин С. П., Шумилин С. П. (2007) Скоростно-силовая подготовка в восточных единоборствах : учебное пособие. Красноярск : Сибирский федеральный университет, Институт естественных и гуманитарных наук, $153 \mathrm{c}$.

14. Санников В. А., Воропаев В. В. (2006), Теоретические и методические основы подготовки боксера, Москва: Физическая культура, 261 с.

15. Филимонов В. И. (2000), Бокс. Спортивно-техническая и физическая подготовка: учебное пособие. Москва, 425 с.

16. Холодов Ж. К., Кузнецов В. С. (2003), Теория и методика физического воспитания и спорта. Москва: Академия, 480 с.

17. Шундеев А. А. (2009), «Многофакторная система оценки в смежных видах единоборств (бокс, кикбоксинг) у спортсме- 


\title{
СЛОБОЖАНСЬКИЙ НАУКОВО-СПОРТИВНИЙ ВІСНИК
}

нов в возрасте от 10 до 18 лет», Физическое воспитание студентов творческих специальностей, № 2, С. 149-159.

18. Яремко М. О. (2001), Вдосконалення швидкісно-силових якостей в ударних прийомах кікбоксерів на етапів попередьної базової підготовки: автореф. дис... канд.. н. з фіз.вих. та спорту: 24.00.01 Олімпійський та професійний спорт. Львів, 22 с.

Стаття надійшла до редакції: 30.11.2020 р.

Опубліковано: 21.12.2020 p.

\begin{abstract}
Аннотация. Юрий Шестак, Вячеслав Мулик, Дарья Окунь. Влияние использования специальных упражнений на психофизиологические показатели юных боксёров 15-16 лет. Цель: определить эффективность применения специальных упражнений с использованием боксерских снаряжений в течение годичного макроцикла у юных боксеров 15-16 лет. Материал и методы: исследования проводились с привлечением юных боксеров 15-16 лет, которые составили контрольную (12 спортсменов) и экспериментальную (12 спортсменов) группы, которые осуществляли годичный тренировочный процесс по программе ДЮСШ, но в экспериментальной группе в конце каждой тренировки использовались упражнения с применением боксерских снаряжений (упражнения с мешком и грушей, с настенной подушкой; пневматической грушей; упражнения с мячом на резинках; упражнения с малым подвесным мячом). Начальное и заключительное измерения психофизиологических показателей осуществлялись после тренировки с большой нагрузкой, которая использовалось у боксеров обеих групп. Результаты: полученные результаты позволяют расширить методику использования специальных упражнений для развития скоростносиловых качеств в соответствии со спецификой вида спорта. Определена целесообразность использования упражнений специальной скоростно-силовой направленности в юных боксеров 15-16 лет в конце тренировочного занятия на фоне усталости. Выводы: подтверждено улучшение результатов психофизиологических показателей, которые являются составляющими двигательной деятельности боксеров (времени простой реакции на звук и свет; пробы Ромберга, показателей теста Шульте, концентрации и переключения внимания по тесту Бурдона).
\end{abstract}

Ключевые слова: юные боксёры, психофизиологические показатели, специальное боксёрское снаряжение, скоростносиловые качества.

Abstract. Yuri Shestak, Viacheslav Mulyk, Daria Okun. Influence of the use of special exercises on the psychophysiological indicators of young boxers aged 15-16. Purpose: to determine the effectiveness of the use of special exercises using boxing equipment during a one-year macrocycle in young boxers 15-16 years old. Material and methods: the research was carried out with the involvement of young boxers 15-16 years old, who made up the control (12 athletes) and experimental ( 12 athletes) groups, who carried out a year-long training process according to the CYSS program, but in the experimental group at the end of each training exercise using boxing equipment (exercises with a bag and a pear, with a wall pillow; pneumatic bag; exercises with a ball on elastic bands; exercises with a small hanging ball). The initial and final measurements of psychophysiological parameters were carried out after training with a high load, which was used in boxers of both groups. Result: the results obtained make it possible to expand the methodology of using special exercises for the development of speed-strength qualities in accordance with the specificity of the sport. The expediency of using exercises of a special speed-strength orientation in young boxers of 15-16 years old at the end of a training session, against the background of fatigue, is determined. Conclusions: the improvement of the results of psychophysiological indicators, which are the components of the motor activity of boxers (the time of a simple reaction to sound and light; Romberg's test, indicators of the Schulte test, concentration and switching of attention according to the Bourdon test) was confirmed.

Keywords: young boxers, psychophysiological indicators, special boxing equipment, speed- strength qualities.

\section{References}

1. Adashevskiy, V. M., Ermakov, S. S., Gritsyuk, S. A. (2010), «Basic kinematic characteristics of shock actions in taekwondo», Fizicheskoe vospitanie studentov, No. 4, pp. 3-5 (in Russ.).

2. Alikin, V. A., Koryagina, Yu. V. (2014), «Modern trends in medical and biological support of highly qualified athletes abroad», Vesnik sportivnoy nauki, No. 3, pp. 50-55 (in Russ.).

3. Anarbaev, A. K. (2013), "The system of training wrestlers, taking into account their qualifications and age», Uspehi sovremennogo estestvoznaniya, No. 1, pp. 112-116 (in Russ.).

4. Ashkinazi, S. M., Klimov, K. V. (2016), Tehniko-takticheskaya podgotovka sportsmenov v kompleksnih (smeshannyih) edinoborstvah [Technical and tactical training of athletes in complex (mixed) single combats]: monografiya / Natsionalnyiy gosudarstvennyiy universitet fizicheskoy kulturyi, sporta i zdorov'ya im. P.F.Lesgafta, Sankt-Peterburg; Voennyiy institut fizicheskoy kulturyi. Sankt-Peterburg, (2-e izdanie, dopolnennoe), 330 p. (in Russ.).

5. Bakulev, S. E., Dveyrina, O. A., Afanaseva, I. A., Chistyakov, V. A. (2013), «Forecasting the success of boxers' competitive activity based on their» sense of time», Uchenyie zapiski universiteta im. P.F. Lesgafta, No. 9, pp. 23-27 (in Russ.).

6. Bakulev, S. E., Taymazov, V. A. (2006), "Genealogical foundations of predicting the success of competitive activity», Uchenyie zapiski universiteta im. P.F. Lesgafta, No. 19, pp. 7-14 (in Russ.).

7. Bogatyirev, S. A. (2016), «Professionally-applied physical training of athletes involved in sports types of single combats», Pedagogiko-psihologicheskie i mediko-biologicheskie problemyi fizicheskoy kulturyi i sporta, No. 1 (38), pp. 8-17 (in Russ.).

8. Haskov, A. V. (2004), Struktura i zmist trenuvalno-zmahalnoi diialnosti v boksi [The structure and content of training and competitive activities in boxing]: monohrafiia / A.V. Haskov, V.A. Kuzmin; Krasnoiar. derzh. un-t, Krasnoiarsk, 112 p. (in Ukr.).

9. Kiprich, S. V., Berinchik, D. Yu. (2015), «Specific characteristics of the functional support of special endurance for boxers», Pedagogika, psihologiya i mediko-biologicheskie problemyi fizicheskogo vospitaniya i sporta, No.3, pp. 20-27 (in Russ.).

10. Lukyanenko, V. P., Volkov, R. A. (2013), «Biomechanical features of boxers' striking movements», Mir nauki, kulturyi, obrazovaniya, No. 4 (41), pp. 85-86 (in Russ.).

11. Mulyk, V. V., Shestak, Yu. S. Okun, D. O.(2019), «The use of special boxing equipment in the general physical training of young boxers 15-16 years», Naukovyi chasopys NPU imeni M.P. Drahomanova, Vypusk 11 (119), pp.184-189 (in Ukr.). 
12. Platonov, V. N. (2017), Dvigatelnyie kachestva i fizicheskaya podgotovka sportsmenov [Motor qualities and physical training of athletes]. Kiev: Olimpiyskaya literatura, 656 p. (in Russ.).

13. Ryabinin, S. P., Shumilin, S. P. (2007), Skorostno-silovaya podgotovka v vostochnyih edinoborstvah [Speed-strength training in oriental single combats]: uchebnoe posobie. Krasnoyarsk: Sibirskiy federalnyiy universitet, Institut estestvennyih i gumanitarnyih nauk, 153 p. (in Russ.).

14. Sannikov, V. A., Voropaev, V. V. (2006), Teoreticheskie i metodicheskie osnovyi podgotovki boksera [Theoretical and methodological foundations of boxer training], Moskva: Fizicheskaya kultura, 261 p. (in Russ.).

15. Filimonov, V. I. (2000), Boks. Sportivno-tehnicheskaya i fizicheskaya podgotovka [Boxing. Sports, technical and physical training]: uchebnoe posobie. Moskva, 425 p. (in Russ.).

16. Holodov, Zh. K., Kuznetsov, V. S. (2003), Teoriya i metodika fizicheskogo vospitaniya i sporta [Theory and methodology of physical education and sport], Moskva: Akademiya, 480 p. (in Russ.).

17. Shundeev, A. A. (2009), «A multifactorial assessment system in related types of martial arts (boxing, kickboxing) among athletes aged 10 to 18 years», Fizicheskoe vospitanie studentov tvorcheskih spetsialnostey, No. 2, pp. 149-159 (in Russ.).

18. Iaremko, M. O. (2001), Vdoskonalennia shvydkisno-sylovykh yakostei v udarnykh pryiomakh kikbokseriv na etapiv poperednoi bazovoi pidhotovky [Improving speed and power qualities in the shock techniques of kickboxers at the stages of preliminary basic training]: avtoref. dys... kand.. n. z fiz.vykh. ta sportu: 24.00.01 Olimpiiskyi ta profesiinyi sport. Lviv, 22 p. (in Ukr.).

Received: 30.11 .2020$.

Published: 21.12 .2020

\section{Відомості про авторів / Information about the Authors}

Шестак Юрій Сергійович: аспірант; Харківська державна академія фізичної культури: вул. Клочківська 99, м. Харків, 61058, Україна.

Шестак Юрий Сергеевич: аспирант; Харьковская государственная академия физической культуры: ул. Клочковская 99, г. Харьков, 61058, Украина.

Yuri Shestak: graduate student; Kharkiv State Academy of Physical Culture: 61058, Kharkiv, st. Klochkivska, 99, Ukraine.

ORCID.ORG/0000-0003-1489-9849

E-mail: oips.hdafk@gmail.com

Мулик Вячеслав Володимирович: д. Фіз.вих., професор; Харківська державна академія фізичної культури: вул. Клочківська 99, м. Харків, 61058, Україна.

Мулик Вячеслав Владимирович: д. физ.восп., профессор; Харьковская государственная академия физической культуры: ул. Клочковская 99, г. Харьков, 61058, Украина.

Viacheslav Mulyk: Doctor of Sciences (Physical Education and Sports), Professor; Kharkiv State Academy of Physical Culture: 61058, Kharkiv, st. Klochkivska, 99, Ukraine.

ORCID.ORG/0000-0002-4441-1253

E-mail: mulyk.viacheslav@gmail.com

Окунь Дар'я Олександрівна: к.фіз.вих.; Харківська державна академія фізичної культури: 61058, м. Харків, вул. Клочківська, 99, Україна.

Окунь Дарья Александровна: к. физ.восп.; Харьковская государственная академия физической культуры: 61058, г. Харьков, ул. Клочковская, 99, Украина.

Daria Okun: PhD (Physical Education and Sport); Kharkiv State Academy of Physical Culture, 61058, Kharkiv, st. Klochkivska, 99, Ukraine

\section{ORCID.ORG/0000-0002-0639-5846 \\ E-mail: dariaokun@gmail.com}

